\title{
La lexicografía bilingüe en la actualidad y su valoración
}

Günther Haensch

Universität Augsburg

Si es cierto que existen unos pocos diccionarios bilingües que cumplen ya con los requisitos de la metalexicografía actual, no es menos cierto que en la mayoría de las librerías se ofrecen, junto a dichas obras, diccionarios anticuados en cuanto al método y al léxico registrado. Para valorar los diccionarios bilingües, propuse en el Tercer Seminario de la Escuela Internacional de Altos Estudios en Lingüistica Aplicada dedicado a los diccionarios bilingües español-otra lengua latina (San Millán de la Cogolla, 23-25 de octubre de 2003) un cuestionario que fue aprobado por los participantes y que debería figurar en las Conclusiones del Seminario. Como allí no aparece, lo ofrezco a los lectores de la Revista de Lexicografía, completado en algunos puntos. Nos tenemos que preguntar, en primer lugar, qué es lo que se debe exigir hoy en día de un buen diccionario bilingüe; para ello puede servir el cuestionario siguiente.

\section{CUESTIONARIO PARA CARACTERIZAR Y VALORAR DICCIONARIOS BILINGÜES}

\section{GRUPO DE DESTINO}

¿Se especifica en el título o en la Introducción el grupo de usuarios al que va destinado el diccionario? Si dice que son turistas, hay que tener en cuenta las situaciones de comunicación que pueden presentarse a este grupo de usuarios y preguntarse si la selección del léxico corresponde a sus necesidades. En el caso de diccionarios escolares bilingües, 
se debe preguntar a qué tipo de alumnos va destinado: ESO, Bachillerato, etc.

\section{INTRODUCCIÓN GRAMATICAL}

¿Hay una introducción gramatical a una de las dos lenguas o a las dos? ¿Se ofrecen cuadros de conjugación de verbos, especialmente irregulares? ¿Se remite en las entradas donde aparecen los verbos irregulares a cuadros de conjugación (si los hay)?

\section{PRONUNCIACIÓN}

¿Hay una introducción a la pronunciación de ambas lenguas o de una de ellas? ¿Se da la transcripción fonética de las palabras registradas en el cuerpo del diccionario? Ésta es irrenunciable para el francés, inglés y el portugués y útil para el alemán; por lo menos, debería darse para esta última lengua en casos problemáticos. En el caso del portugués es deseable que se indique la pronunciación estándar del portugués del Brasil y de Portugal. El problema de la pronunciación que se plantea en italiano es, en primer lugar, la acentuación de las palabras que no se puede deducir de la escritura; algunos diccionarios ponen un acento gráfico en la sílaba acentuada, lo cual desfigura la realidad ortográfica del italiano. El diccionario italiano Herder ${ }^{1}$ ha resuelto muy bien el problema señalando la vocal tónica mediante un subrayado.

\section{INSTRUCCIONES PARA EL USUARIO}

¿Son claras y suficientes las instrucciones sobre el manejo del diccionario o no hay instrucciones?

\section{GRAMÁTICA EN EL DICCIONARIO}

5.1. ¿Se dan las indicaciones gramaticales necesarias? Para éstas se usan siglas llamadas marcas gramaticales.

1 Cesáreo Calvo Rigual y Anna Giordano, Diccionario italiano. I. Italiano-Español, Barcelona, Herder, $1998^{3}$. 
5.2. ¿Se indica la categoría gramatical de las palabras como sustantivo, adjetivo, etc.?

5.3. ¿Se indica sistemáticamente el género de los sustantivos y la forma femenina de los adjetivos y especialmente de los sustantivos que denominan una profesión, actividad o actitud (nomina agentis)? Esta última indicación es muy importante desde que las mujeres ejercen prácticamente todas las profesiones reservadas antes a los hombres. El usuario puede tener dudas sobre si es correcto la juez o la jueza, la ministro o la ministra, y necesita información en casos difíciles como la soldado, la piloto, la miembro.

¿Se indican los plurales irregulares de los sustantivos y adjetivos? Así, por ejemplo, en el español régimen-regímenes, en el francés général-généraux, en el alemán Licht-n 1. “luz" f. pl Lichter; 2. (vela) pl. Lichte.

5.4. Régimen y construcción: ¿Se indica el régimen preposicional de verbos, adjetivos y sustantivos? Esta indicación tan importante para producir enunciados lingüísticos se echa de menos en muchos diccionarios.

5.5. Formas difícilmente identificables de verbos: ¿Se registran como lemas en el cuerpo de los diccionarios las formas irregulares de verbos difícilmente identificables, remitiendo a la forma del infinitivo? Ejemplos en español: irgo (erguir), cupo (caber), quiso (querer); en inglés: stuck (to stick), wept (to weep); en alemán: trug (tragen), pries (preisen), etc.

\section{COMPUESTOS Y FRASEOLOGISMOS}

¿Se tienen en cuenta suficientemente las unidades pluriverbales relacionadas con el lema, como pueden ser sintagmas nominales, colocaciones, locuciones, modismos, etc.?

\section{EJEMPLOS}

Se ofrecen ejemplos de uso en forma de frases-ejemplo? ¿Se trata de citas procedentes de un corpus de textos o de ejemplos inventados por el lexicógráfo? 


\section{SELECCIÓN DEL LÉXICO}

¿Es acertada la seleción del léxico? Para averiguar esto, nos tenemos que fijar en la presencia o ausencia de los siguientes tipos de léxico:

8.1. Léxico de nuestra civilización actual sujeto a cambios constantes.

8.2. Léxico del lenguaje coloquial actual.

8.3. Léxico del lenguaje vulgar.

8.4. Americanismos usuales.

\section{FiabiLidAd DE LOS EQUIVALENTES}

¿Son fiables los equivalentes en la lengua de destino que da el diccionario? Hasta en buenos diccionarios hemos descubierto equivalencias incorrectas.

\section{AbreViaturas y Siglas}

¿Se registran las abreviaturas y siglas más frecuentes, como en España PSOE, PP, IVA, IRPF, ATS?

\section{ACOTACIÓN EXACTA DE LAS DiSTINTAS ACEPCIONES DE UNA PALABRA}

Estas delimitaciones se pueden hacer mediante marcas lexicográficas o glosas.

11.1. Las marcas estandarizadas pueden ser de especialidad, por ejemplo, agricultura, medicina, sobre la extensión geográfica del uso, por ejemplo, Andalucía, Perú, y estilisticas (diafásicas) como, por ejemplo, coloquial, vulgar, irónico, humorístico, etc. En los diccionarios debe haber una lista de todas las marcas que aparecen en él, en las primeras páginas o en la contraportada de la obra.

11.2. Las glosas son palabras o frases cortas aclaratorias no estandarizadas sobre el uso de la palabra que aparecen en letra cursiva y entre paréntesis delante de cada acepción, por ejemplo, en un diccionario español-francés: junco $m 1$. bot jonc $m$; 2. (embarcación) jonque $f$. Otro ejemplo: para el verbo poner habría que indicar en un diccionario 
bilingüe: (colocar)...; (telegrama)...; (un anuncio en un periódico)...; (cosas en orden)...; (huevos)...; (la mesa)...(en una apuesta); etc. Las glosas permiten también señalar en qué situaciones de comunicación se usa una palabra, por ejemplo, la glosa "(usado por antifascistas)" para facha, o la glosa "(usados como apelativo entre jóvenes)" para tio o macho.

\section{ORDEN ALFABÉTICO}

¿Se ha respetado en los diccionarios que interesan el orden alfabético del español introducido en 1994 o aparecen todavía la CH y la LL como letras independientes?

\section{INNOVACIONES EN LOS DICCIONARIOS BILINGÜES}

En los últimos quince años se han introducido varias novedades en los diccionarios bilingües:

13.1. En algunos diccionarios el lema se imprime en letras de color (rojo o azul) para que destaque más.

13.2. En otros diccionarios se ofrecen recuadros dentro del cuerpo del diccionario. En éstos se tratan:

a) problemas gramaticales como el uso del subjuntivo

b) Se explican palabras pertenecientes al léxico de civilización (culture-specific-words) prácticamente intraducibles, como flamenco, paella, botellón, Mesta, jota, movida. Esta innovación es de saludar porque resuelve el problema del léxico de civilización mediante una breve definición ya que no se puede dar un simple equivalente en la lengua meta. Algunos diccionarios registran en los recuadros nombres propios de personas como Carlos V, Pizarro, Dalí, estos nombres deberían figurar en un diccionario enciclopédico o en una enciclopedia y no en un diccionario bilingüe.

c) ¿Se comentan casos de falsos amigos? Recordemos que son palabras formalmente idénticas o parecidas, pero de significado diferente. Ejemplo: estar constipado significa en español "estar res- 
friado o acatarrado", en francés, en cambio, être constipé quiere decir "tener estreñimiento".

\section{OTROS EXTRAS}

Además de los recuadros, algunos diccionarios ofrecen diferentes tipos de anexos o textos intercalados entre las dos partes de un diccionario bilingüe:

a) Una breve introducción a la civilización de los países cuyas lenguas interesan

b) una guía de conversación que ofrece frases que corresponden a situaciones de comunicación muy frecuentes en la vida diaria.

c) Modelos de cartas privadas y comerciales

Todos estos "extras" pueden ser útiles siempre que no sean tan sólo un argumento de publicidad editorial. Para las frases usuales en la conversación existen guías de conversación; para las cartas hay guías de correspondencia. Personalmente preferiría que se aprovechasen las páginas que se gastan en extras para poner más fraseología y más léxico actual; los extras útiles son los de léxico de civilización y de falsos amigos. 